\title{
LA TEORÍA DE LA PUERTA EN LA ENSEÑANZA DE LENGUAS
}

\author{
Pablo Martínez Menéndez \\ Universidad de Oviedo \\ http://dx.doi.org/10.18778/8220-201-4.17
}

\section{Resumen}

En el proceso enseñanza-aprendizaje de lenguas la cultura ha ido cobrando importancia hasta tal punto que, en la mayoría de los métodos actuales, la lengua necesita entenderse dentro del contexto cultural en que se utiliza. La teoría de la puerta señala dos enfoques: uno para Español como Lengua Extranjera (ELE) y otro para Español con Fines Específicos (EFE) que permiten aprovechar al máximo la herramienta cultural.

Palabras clave: Lengua, cultura, Español Lengua Extranjera, Español con Fines Específicos.

Este trabajo versa sobre la importancia de la cultura en la didáctica de lenguas. Al mismo tiempo, pretendemos realizar una apología del papel del profesor, pues, cuando se trata de la docencia, no cabe hablar de materiales buenos o malos o de planteamientos mejores o peores, si no se recalca una idea clave: depende de quién los utilice y cómo lo haga.

Del ilustre actor José M. ${ }^{\text {a }}$ Rodero se comentaba que era capaz de interpretar hasta una factura de la luz (cosa harto difícil en estos tiempos, como sabrá quien haya tratado de entender el precio de la electricidad). Al igual que Rodero, existen profesores que logran extraer, de textos ínfimos, brillantes clases, o excelentes actividades, de materiales aparentemente inservibles. De ahí que todo lo que a continuación expondremos venga condicionado por la habilidad de los docentes al utilizarlo. 
Una dificultad habitual en la enseñanza de segundas lenguas reside en el contexto sociocultural en que estas se desarrollan. No es la única dificultad con la que se encontrarán los alumnos y, como las otras, hallarán el modo de salvarla. Recordemos que en el Marco Común Europeo de Referencia para las lenguas (MCER), entre las estrategias de aprendizaje, concretamente entre las comunicativas, se mencionan las evitativas y las compensatorias ${ }^{1}$. Las evitativas, como su propio nombre indica, consisten en tratar de evitar los errores en la comunicación mediante el silencio o, al menos, la reducción drástica del contenido del mensaje. Sirva como ejemplo un estudiante vegano que acabó comiéndose un chuletón de buey por no disponer del vocabulario para rechazarlo. Las compensatorias, por el contrario, se utilizan cuando se desea perseverar en el esfuerzo comunicativo: se buscan alternativas al mensaje para paliar las carencias, por medio de circunloquios, con ejemplos, metáforas...

Precisamente las metáforas forman parte del lenguaje poético, tal vez el más complicado (junto con el humorístico) para los estudiantes desde el punto de vista cultural. A menudo los estudiantes desconocen la mayoría de las referencias que aparecen en los textos (en un sentido amplio que incluye también el discurso oral). En consecuencia, no logran establecer la conexión que (en el caso del humor) permite entender la gracia y (en la poesía) las connotaciones.

En efecto, el humor se basa en un mecanismo aparentemente sencillo mediante el cual se quiebran las expectativas y se sorprende con lo inesperado; por supuesto, con una condición: que esa sorpresa cuente con una justificación. Que puedan trazarse unas conexiones entre lo esperable y lo sorprendente. Dichas conexiones suelen venir condicionadas por el contexto, y el contexto, con frecuencia, depende exclusivamente de la cultura.

El término "cultura" (como casi todos los términos) resulta ambiguo. Tradicionalmente se interpretaba como un concepto elitista (aún en nuestros tiempos aparece en expresiones como "la

1 Se mencionan, pero no se explican con detenimiento, aunque resulta evidente su importancia durante el proceso enseñanza-aprendizaje. 
gente de la cultura") y se asociaba con los conocimientos enciclopédicos. Este tipo de cultura era el único que encontraba cabida en métodos como el de gramática-traducción. Con la evolución de la didáctica de lenguas se amplió la idea de cultura, de modo que no solo las artes o las ciencias sino también determinados comportamientos y costumbres se acomodaban a dicha idea ${ }^{2}$.

El proceso de enseñanza-aprendizaje de una segunda lengua se presenta ligado a la cultura de los países en los que esta se ha$\mathrm{bla}^{3}$. Algunas lenguas se circunscriben a un determinado entorno geográfico, lo que acota los límites culturales; otras, sin embargo, cuentan con una mayor diversidad, lo que repercute en más dificultades a la hora de aproximarse a esos contextos, por su variedad. Evidentemente, el entorno cultural del polaco se ciñe a los límites geográficos de Polonia (o, todo lo más, hasta el Condado de Vilna, en Lituania). Sin embargo, para un estudiante de español, este se inserta en culturas muy diferentes (México, Cuba, Perú, Chile, Argentina... la propia España), lo que supone una complicación añadida a la tarea de enseñar-aprender la lengua.

Para un docente, el desconocimiento de la cultura por parte de los alumnos significa un reto que no siempre está dispuesto a asumir. Si recordamos las estrategias evitativas antes mencionadas, descubrimos que no pertenecen en exclusiva al estudiante: los profesores tratan de evitar complicaciones, así que renuncian a explotar actividades que impliquen un gran conocimiento de la cultura y que cuenten con numerosas referencias culturales. En la mente de muchos docentes existe la idea de que cada una de estas representaciones del acervo cultural se convierte en un escollo insalvable para el alumno en su periplo por las procelosas aguas de la lengua. Se rechazan ejercicios cuya dificultad reside

2 La idea de contraponer a "Cultura" (con mayúscula) "kultura" (con ka) la podemos encontrar en Miquel y Sans y establece la diferencia entre carácter enciclopédico y carácter popular en los contenidos culturales. Se basa, como resulta evidente, en la distinción Kultur/ kultur del alemán ante esta misma dicotomía.

3 Según plantean De Grève y Van Passel (1971), no cabe desligar la enseñanza lingüística de la cultural, pues la propia lengua representa uno de los aspectos más destacados de una cultura. 
precisamente en la correcta interpretación del texto a través del filtro de la cultura, al asumir que la condición de extranjero limita la comprensión por resultarle ajenos los contenidos.

No obstante, asentar las diferencias culturales en los límites estrictamente geográficos implica reducir drásticamente la variedad de estas. En efecto, si ya un mejicano percibe dificultades culturales en el discurso de un español (y viceversa), y aún un andaluz en el de un asturiano, para alguien con otra lengua materna el acceso a nuestra cultura exige un enorme esfuerzo. Sin embargo, las mismas dificultades se encuentran en lindes generacionales.

La tira cómica de Gallego y Rey solo logra su efecto humorístico si el lector comprende sus referencias culturales. Necesita saber que Machado era un poeta sevillano; que Alfonso Guerra, vicepresidente del Gobierno de España entre 1982 y 1991, regentaba la librería "Antonio Machado", y que se le consideraba experto en dicho autor; que en 1990, año de la publicación de la tira, Guerra inauguró en Turín el Congreso Internacional Machadiano; que uno de los versos más famosos del poeta, perteneciente a su Retrato, "Mi infancia son recuerdos de un patio de Sevilla", se completa con "un huerto claro donde madura el limonero"; que en 1990 Guerra sufría una campaña de desprestigio por los supuestos negocios ilegales de su hermano Juan, al que presuntamente había ayudado desde su posición privilegiada.
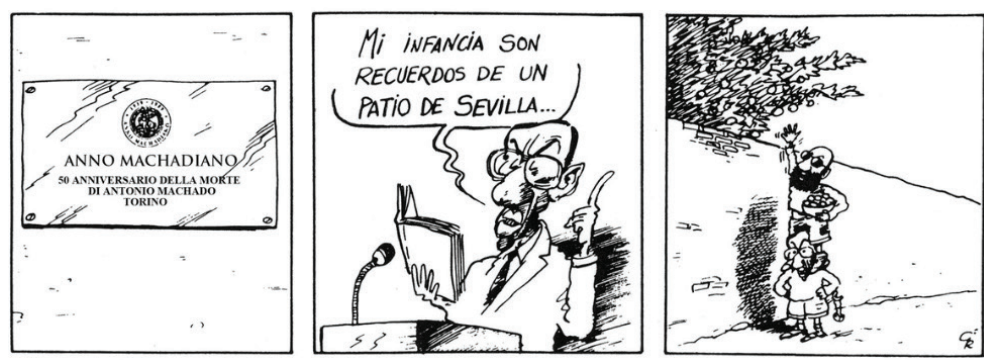

Imagen 1. Tira cómica de Gallego y Rey en Diario 16 (1989)

Un extranjero probablemente carezca de dichas referencias culturales... igual que un español nacido después de la década de los setenta. En este caso la nacionalidad puede ser condición necesaria (pero no suficiente) para lograr entender: existe, pues, 
una estratificación de la cultura incluso cuando se intenta ceñir a una cuestión territorial. No solo la pertenencia a una generación u otra facilita o dificulta desentrañar las claves de estas referencias culturales; los propios intereses condicionan las interpretaciones. A continuación, presentamos algunos ejemplos de enunciados que únicamente conocerán personas con una determinada edad o con aficiones específicas.

Tabla 1. Frases populares en España por categorías y épocas
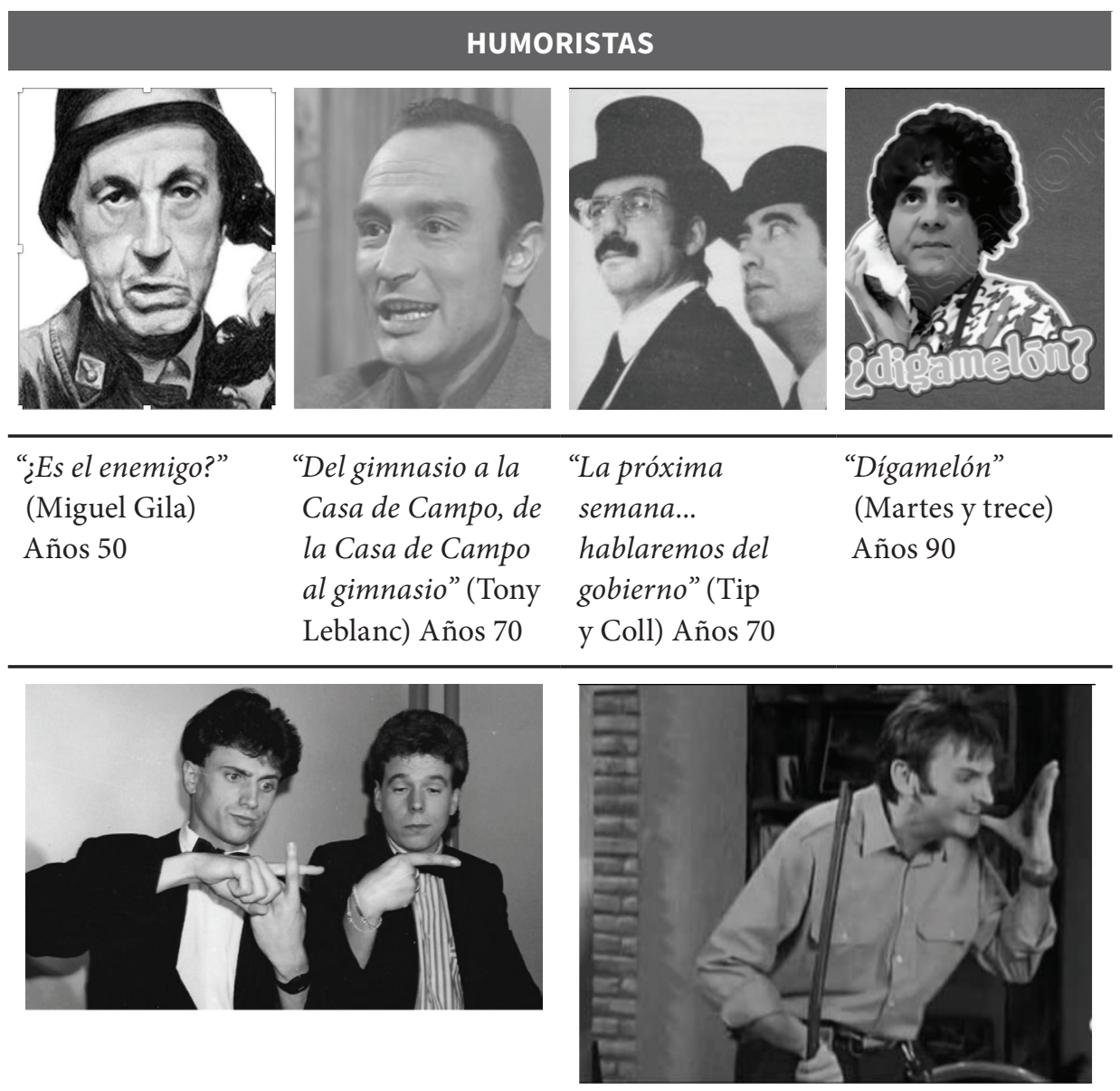

"Si hay que ir se va, pero ir para na'

"Un poquito de por favor"

es tontería” (Cruz y Raya) Años 2000

(“Aquí no hay quien viva”) Años 2000 


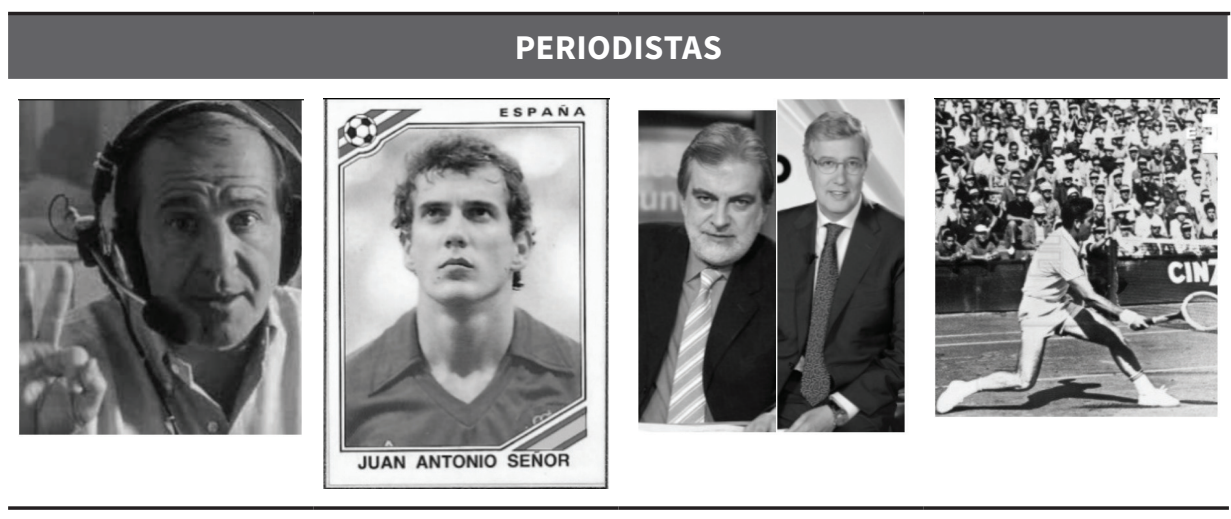

\begin{tabular}{llll}
\hline “Ojo al dato!” & “Gol de Señor!” & "Así son las cosas & "Entró, entró” \\
(José M. a García) & (José Ángel de la & y así se las hemos & (Juan José \\
Años 80 & Casa) Años 80 & contado” (Mariñas & Castillo) Años 60 \\
& & y Buruaga) \\
& & Años 90
\end{tabular}

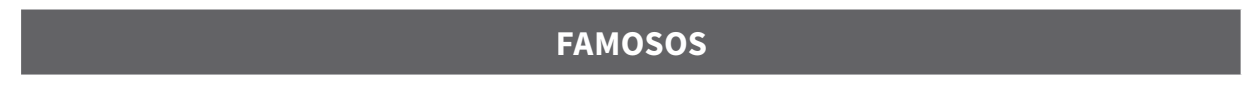

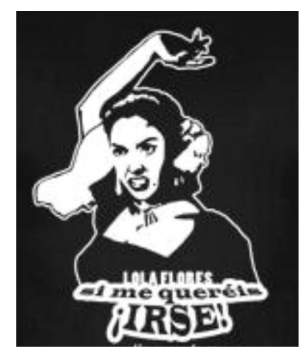

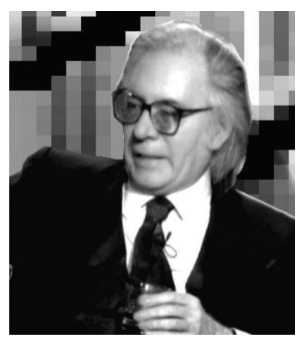

"Si me queréis... ¡irse!” (Lola Flores) Años 80
"Yo he venido

a hablar de mi libro" (Paco Umbral) Años 90
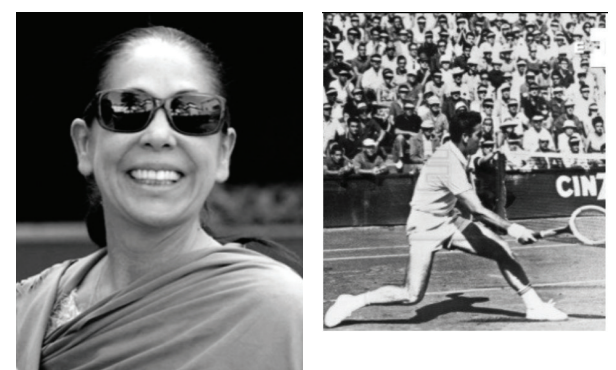

"Dientes, dientes, que es lo que les jode" (Isabel Pantoja) Años 2000
“Trata de arrancarlo, por Dios, Carlos! ¿Trata de arrancarlo!"

(Carlos Sainz)

Años 2000 


\section{PUBLICIDAD}
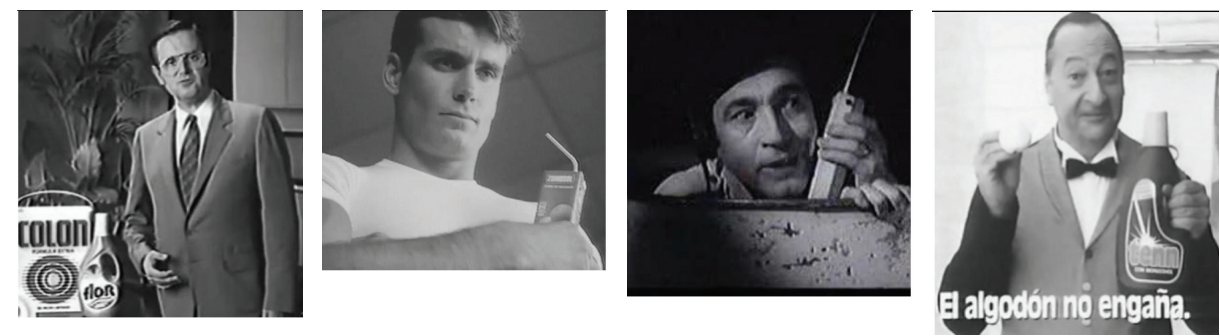

"Busque, compare

$y$, si encuentra algo mejor, cómprelo"

(Manuel Luque, director general de CAMP) Años 80
"Mi primo el de Zumosol" (Zumosol) Años 90"

Años 90
“ $\mathrm{Y}$ da un gustirrinín!” (Filomátic) Años 70

"El algodón no engaña” (Tenn) Años 80

\section{TELEVISIÓN}
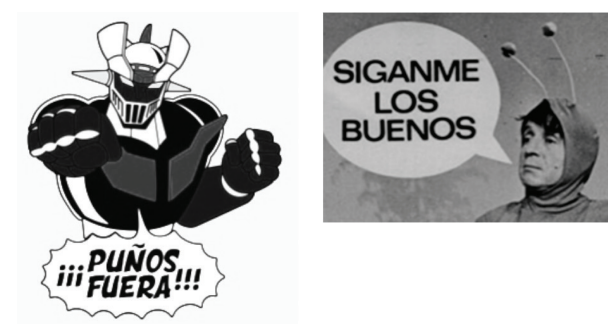

“¡Puños fuera!”

(Mazinger Z)

Años 70

\begin{abstract}
“¡Síganme los buenos!” (El

Chapulín

Colorado) (Años
\end{abstract}

70)
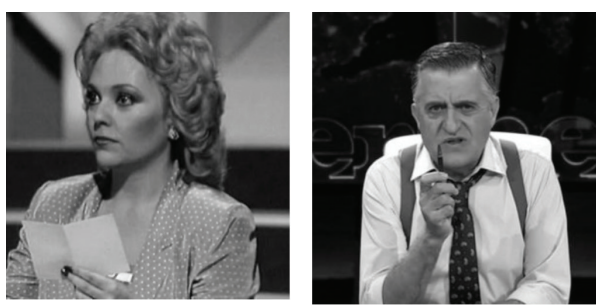

“Mañana más, pero no mejor, porque es imposible." (Gran Wyoming, El intermedio)

Años 2000

La existencia de innumerables subconjuntos dentro lo que se denomina "cultura" imposibilita la idea de que para aprender una lengua se necesite dominar dicha cultura; todo lo más, acceder a ella a través de los intereses y conocimientos que resulten más cercanos al alumno. En este sentido consideramos paradigmático el aprendizaje de lenguas con fines específicos. En efecto, desde 
época muy antigua se valoró el dominio de lenguas extranjeras por motivos varios. En La Regenta, de Leopoldo Alas “Clarín”, se describe a un respetado caballero apoplético que se siente en la obligación de leer la prensa internacional debido a sus negocios de exportación de grano. Dicho caballero se quedaba dormido sobre el primer periódico del mundo. Cuando murió, de apoplejía, se descubrió que no sabía inglés.

El más digno de consideración, entre los abonados al gabinete de lectura, era un caballero apoplético, que había llevado granos a Inglaterra y se creía en la obligación de leer la prensa extranjera. Llegaba a las nueve de la noche indefectiblemente, tomaba Le Figaro, después The Times, que colocaba encima, se ponía las gafas de oro y arrullado por cierto silbido tenue de los mecheros del gas, se quedaba dulcemente dormido sobre el primer periódico del mundo. Era un derecho que nadie le disputaba. Poco después de morir este señor, de apoplejía, sobre The Times, se averiguó que no sabía inglés (Alas, [1884] 2011: 104).

En este maravilloso fragmento aparecen dos de las principales razones para aprender lenguas: la consideración social y los negocios. En el segundo caso se incluyen las lenguas con fines específicos, cuyos cursos suelen asentarse sobre un planteamiento, en nuestra opinión, incorrecto y fraudulento. Estos cursos se presentan como la clave para que personas que desconocen la lengua meta consigan usarla en su ámbito laboral. Así, existen, por ejemplo, cursos de Español para vitivinicultores con los que se pretende preparar a dichos empresarios para desenvolverse en nuestra lengua en diversas situaciones relacionadas con su trabajo. El objetivo dista mucho de ser el dominio del español: únicamente se intenta dotar de determinadas estructuras y de un léxico especializado a estos alumnos, de modo que logren superar con éxito algunas situaciones comunicativas habituales y previsibles. Recalcamos lo de "previsibles" porque aquí radica el quid de la cuestión: la producción del alumno, si se limita a una simple exposición oral, no reviste especial dificultad. El problema aparece 
cuando esa exposición oral se convierte en una interacción oral, en la que no se controla qué puede decir el interlocutor.

Evidentemente, las lenguas se aprenden progresivamente, pero no sectorialmente. En los primeros niveles se adquieren conocimientos básicos, y solo a partir de unos mínimos necesarios se comienza la especialización. Resulta inasumible pensar en un estudiante incompetente a la hora de entender frases cotidianas, pero capaz de explicar las diferencias entre vinos o su proceso de elaboración (explicar y no repetir de memoria). Esto se puede extrapolar a cualquiera de los múltiples cursos de lenguas específicas que se ofrecen, excepción hecha de la lengua con fines académicos, por su exigencia inherente. Sin embargo, la enseñanza de lenguas específicas se ha incrementado en los últimos años; cada vez más estudiantes de mentalidad utilitarista se preocupan por aprender una lengua dirigida a sus intereses más concretos, entre los que destaca el laboral. De nuevo se encuentra esa estratificación cultural asociada a una lengua determinada.

Los juristas, los economistas, los médicos... Cada grupo de profesionales comparte unos conocimientos que se reflejen principalmente en el léxico, pero también en algunas estructuras gramaticales.

La primera acepción de la palabra "puerta" que recoge el DRAE "la define como un vano de forma regular abierto en una pared, una cerca, una verja, etc., desde el suelo hasta una altura conveniente, para poder entrar y salir por él". Atendiendo a estas últimas palabras, que la puerta dispense un servicio bidireccional permite entrar o salir. Puesto que la relación entre lengua y cultura comparte esa cualidad bidireccional, un cambio de perspectiva permite aprovechar la cultura como llave hacia la lengua. Los obstáculos culturales antes señalados se convierten de esta manera en estímulo e impulso para el aprendizaje.

Se cuenta la anécdota de un noble francés al que le llegaron rumores de que el rey había indagado si sabía castellano; de inmediato comenzó a tomar lecciones suponiendo que el monarca pensaba concederle su embajada en España. Meses después el rey se le acercó y le interpeló sobre su dominio de nuestra lengua. El noble respondió en perfecto castellano y el rey lo felicitó: 
“Enhorabuena, ahora podrá disfrutar de la genial obra de Cervantes en su lengua original!"

Y aunque no abunden los casos de personas que aprenden una lengua con el único fin de disfrutar de un libro (Freud aprendió español para poder leer el Quijote), este tipo de gustos pueden sumarse a los objetivos iniciales a medida que se conoce la cultura de su entorno. Si bien el aprendizaje de la lengua se dirige con frecuencia a intereses profesionales o académicos con expectativas crematísticas, los aspectos culturales suponen un aliciente: disfrutar de Cien años de soledad, de los poemas de Alberti; entender el humor de Les Luthiers o Miguel Gila; escuchar las canciones de Violeta Parra, Víctor Jara, Joaquín Sabina...

Las actividades impregnadas de referencias culturales implican un esfuerzo tanto para el estudiante como para el docente; requieren más explicaciones y una mayor preparación que otro tipo de ejercicios. Sin embargo, se trata del mismo reto de superar obstáculos y coronar la cima que impulsa a los alpinistas. Ese desafío ofrece como premio, además de la propia superación personal, el acceso a una parte de la cultura en que se desarrolla la lengua meta. Recae sobre el docente la responsabilidad de seleccionar los materiales más adecuados para el estudiante, lo que significa decidir qué capas de la cultura pueden aparecer.

Como ejemplo presentamos una canción de Javier Krahe titulada "Ciencias ocultas", poblada de referencias culturales específicas de España.

En la canción se detectan aspectos socioculturales: "catorce y jueves" frente a "trece y martes", tradicional día de la mala suerte en España ("En trece y martes... ni te cases ni te embarques"). “Te pone cuernos", engañar y burlar, en este caso hasta la luna llena (fase en la que la luna no tiene cuernos, al contrario que en los cuartos crecientes y menguantes). "Envido", expresión típica de juegos de cartas, como el mus, con la que se apuesta: evidentemente poco tiene que ver con las cartas del tarot, lo que demuestra la poca pericia como bruja. "Aquelarre" (del vasco "ake" y "larre”, macho cabrío en el prado"), es una reunión de brujas. "Arre, [escoba], arre", interjección con la que normalmente se estimula a los caballos para que se pongan en marcha o aceleren. 
El juego de palabras entre "astrología" y "desastre". "Mi mamá me mima”, frase típica de las cartillas y con la que se practica el fonema $/ \mathrm{m} /$.

Tabla 2. Letra de la canción "Ciencias ocultas", de Javier Krahe.

\begin{tabular}{|c|c|}
\hline $\begin{array}{l}\text { Grave desencanto te ha dado a resultas, } \\
\text { del cual te dedicas ahora a las ciencias } \\
\text { ocultas. }\end{array}$ & $\begin{array}{l}\text { Si hasta tu lechuza se volvió a su nido, } \\
\text { desde que al tarot te oyó exclamar: } \\
\text { “Envido!” }\end{array}$ \\
\hline $\begin{array}{l}\text { Tú que ya eras torpe de racionalista, } \\
\text { no lo tienes fácil, Satanás te asista. } \\
\text { Siendo solo fea, siendo solo arpía, } \\
\text { nunca serás bruja de categoría. }\end{array}$ & $\begin{array}{l}\text { Dudo que aterrices en el aquelarre, } \\
\text { por mucho que azuces “¡arre, escoba, } \\
\text { arre!”. }\end{array}$ \\
\hline $\begin{array}{l}\text { Prueba fehaciente de tus pocas luces: } \\
\text { en vez de manzanas llevas altramuces } \\
\text { y haces tus conjuros en catorce y jueves, } \\
\text { así no te pica ni una Blancanieves. }\end{array}$ & $\begin{array}{l}\text { Que una buena bruja sabe alzar el vuelo, } \\
\text { tú nunca has podido despegar del suelo. } \\
\text { Júpiter, Saturno, Marte y compañía } \\
\text { ¡qué lejos te caen, qué desastrología!. }\end{array}$ \\
\hline $\begin{array}{l}\text { Dan tus sortilegios tal vergüenza ajena } \\
\text { que te pone cuernos incluso la luna } \\
\text { llena. }\end{array}$ & $\begin{array}{l}\text { Verte leer las manos, la verdad, da } \\
\text { grima; } \\
\text { siempre balbuceas: "Mi mamá me } \\
\text { mima”, }\end{array}$ \\
\hline $\begin{array}{l}\text { Aunque eches los polvos de la madre } \\
\text { Celestina, } \\
\text { tus filtros de amor dejan pasar la } \\
\text { nicotina }\end{array}$ & $\begin{array}{l}\text { Todos tus horóscopos, tus cartas } \\
\text { astrales, } \\
\text { lo dicen bien claro: para bruja tú no } \\
\text { vales. }\end{array}$ \\
\hline $\begin{array}{l}\text { y al ponerte bizca con la bola esa, } \\
\text { el futuro más vulgar se te atraviesa. }\end{array}$ & $\begin{array}{l}\text { Siendo solo fea, siendo solo arpía, } \\
\text { no lo tienes fácil ni en la brujería. }\end{array}$ \\
\hline
\end{tabular}

Retomando los cursos de lenguas con fines específicos, de nuevo el papel de la cultura favorece el aprendizaje si se enfoca con esta idea de puerta para acceder a la lengua. Si resulta imposible aprender una lengua extranjera parcialmente, limitada estrictamente a un ámbito determinado (que es como se ofrecen dichos 
cursos de manera habitual), sin embargo, parece razonable aprovechar los conocimientos previos del alumno en lo tocante a su ámbito profesional y a sus intereses, para facilitarle el acceso a la lengua. Así, un médico aprenderá español practicando estructuras gramaticales y un léxico en parte especializado, para situaciones que resulten habituales en su trabajo. Esto no significa que solo pueda usar esas estructuras en su labor profesional: una vez aprendidas, las utilizará en cualquier ámbito e incrementará su léxico paulatinamente.

Como conclusión, el proceso enseñanza-aprendizaje de una lengua requiere un acercamiento a su cultura (a sus culturas, más precisamente); tanto para el docente como para el estudiante implica más empeño y dificultad, pero también ofrece unos mayores beneficios. En el caso del español, si diferenciamos entre ELE (Español como Lengua Extranjera) y EFE (Español con Fines Específicos), la función de la cultura en este proceso varía: mientras que para ELE la cultura significa una atracción, una exposición de la manera de interpretar la realidad a través de nuestra lengua, en EFE facilita los pasos para comenzar a comunicarse en un escenario conocido. O, expresado de otro modo, la cultura en ELE invita a descubrir un nuevo mundo, mientras que en EFE sirve de guía para no perderse en él.

\section{Referencias bibliográficas}

Alas (Clarín), L. ([1884] 2011), La Regenta, Madrid: Literanda.

Consejo de Europa (2002), Marco común europeo de referencia para las lenguas: aprendizaje, enseñanza, evaluación, Madrid: Ministerio de Educación, Instituto Cervantes y Anaya.

De Grève, M., Van Passel, F. (1971), Lingüística y enseñanza de lenguas extranjeras, Madrid: Fragua.

Miquel, L., Sans, N. (1992), "El componente cultural: un ingrediente más en las clases de lengua”. Cable 9, 15-21. 